\title{
Parsimony, Evolution, and Animal Pain
}

\author{
Robert P. Rosenfeld \\ University of Massachusetts \\ Boston
}

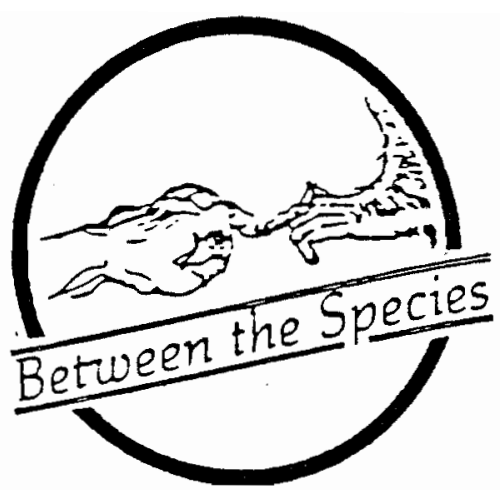

such doubts are not sufficiently strong to outweigh the moral costs of judging wrongly against animals. For a stronger case, genuinely positive evidence from neurophysiology, rather than a priori theorizing from evolutionary biology, will be required.

Harrison attacks the combined analogical argument on the basis of skepticism about the relationships between neurophysiology, behavior, and mental states. Since studies indicate that the relationships between neural structures and mental states are not nearly as straightforward as once believed, one cannot, according to Harrison, appeal to similarities in human and animal neural structure and function to support the conclusion that humans and animals have similar mental pain states. ${ }^{1}$

A major weakness of this kind of skeptical response is that it can also be directed against the claim that our fellow humans feel pain. Harrison's problem then is to justify the ascription of mental pain states to humans but not to animals. ${ }^{2}$ Harrison might try to base a case for this on the disanalogies between human and animal neurophysiology, particularly those involving neocortical structures that might be associated with pain. However, Harrison does not do this, at least in part because his skepticism about such relationships itself seems to disallow it. It would be ironic for speciesists if such skepticism ended up dismissing some of the best evidence we might have for human superiority.

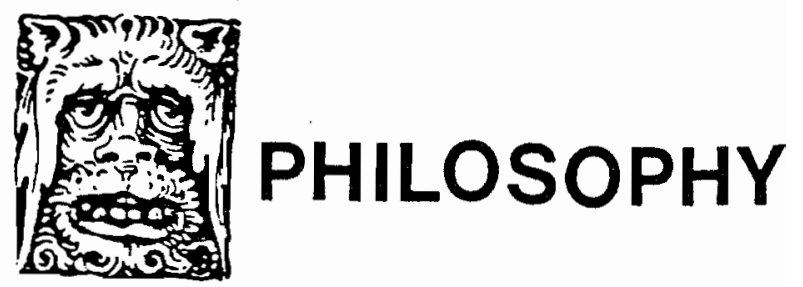


Another problem is that some of Harrison's skeptical evidence can be used just as readily against his position as in support of it. Harrison cites, for example, the case of "thin-brained" human individuals, whose skulls are mostly fluid-filled space, with a thin layer of brain tissue pressed against the skull. Many of these individuals, far from being "vegetables," seem to have normal cognitive abilities, and are of apparently normal, or above normal, intelligence. ${ }^{3} \mathrm{He}$ also notes the ability of birds to "see" in spite of the fact that they have no region of their brain corresponding to our visual cortex. In fact, the neurophysiological architecture associated with their vision is quite different from ours. ${ }^{4}$ However, such cases could just as well support the possibility that animals with tiny brains, or with very different brains from ours, feel pain. ${ }^{5}$ If we combine this possibility with the moral argument for giving animals the benefit of the doubt, we might need to give this benefit to roaches and flatworms as well as to apes and rabbits.

This moral benefit of doubt enters here because the skeptical argument is, in the end, neutral concerning the existence of mental pain states in animals. Animals might feel pain or they might not. A morally isolated epistemology might lead us to prefer non-mentalist parsimony here. As moral agents, however, we must consider the costs of being wrong: if we are to be wrong, it is better to err on the side of kindness than on that of cruelty. Although this position cannot be accepted without qualification, I will pass over such qualification, both because of limited space and because Harrison in fact recognizes its force, using it as part of the reason for pursuing his other line of argument. ${ }^{6}$

In an effort to justify denying pain to animals but not to humans, and to provide a positive argument against the existence of animal pain that is sufficiently strong to counteract the moral benefit of doubt, Harrison resorts to evolutionary theory. According to Harrison, evolution would not favor the development of mental pain states except in a being capable of determining its action on the basis of reasons rather than instincts or reflexes. Furthermore, only a being capable of making free choices can act on the basis of reasons. Since humans, but not animals, base their actions on reasonssince humans, but not animals, make free choices-it is only in humans that the evolution of mental pain states constitutes a reasonable evolutionary development or adaptation. For Harrison, mental pain states serve a necessary function only as a "voice of the body in the deliberations of the mind, and only in a being that can overrule the body's demands in favor of consciously chosen objectives. ${ }^{7}$

Harrison's case can be attacked in two ways: First, one can argue that animals do in fact act on the basis of reasons, and that they do make free choices. Alternatively, one can argue against the need for a connection between reason-based choice and pain. I will pursue the latter path here, since that focuses on Harrison's misuses of the notion of parsimony and the theory of evolution.

Harrison depends on appeals to several kinds of parsimony in his argument. One kind he draws upon is that of C. Lloyd Morgan, who held that we should not explain behavior in terms of "higher psychical faculties" when explanations in terms of "lower psychical faculties" suffice. ${ }^{8}$ It seems clear from what Harrison has said that he considers pain to be a "higher" faculty, rather than the primitive "raw feel" that some of us might think it is, an assessment that has found support from studies showing that there is a large cognitive component to human pain perception. ${ }^{9}$

Harrison also appears at times to endorse the position that we should not explain animal behavior in terms of mental states when purely physical-or behavioristic explanations would suffice. ${ }^{10}$ This certainly seems true of his attitude toward animal pain behavior, which Harrison feels can be adequately explained by reflexes and nonmentalistic behavioral principles. It could also be applied, and has been applied by many workers, to support a general denial of conscious states in animals. ${ }^{11}$ It is not clear to me why Harrison does not go all the way with this, and deny the existence of consciousness in animals, not just mental pain states. In fact, in one of his articles, he proposes, although with minimal justification, a temporally-fragmented consciousness for animals. ${ }^{12}$ This generosity may be importantgiven the existence of animal consciousness, the evolutionary usefulness of pain is very defensible, as we will see shortly.

The two kinds of parsimony mentioned so far can be invoked independently of evolutionary theory. An application of two additional parsimony principles (to be mentioned shortly) will yield Harrison's evolutionary position: Since pain is not a necessary feature of animals' consciousness, either for their actual adaptation to their life needs (i.e. for their survival and reproduction), or for our explaining their behavior, then it is not reasonable to suppose that they feel pain. Notice that this kind of argument call be raised against any 
feature of animal consciousness, not just animal pain. This can be seen upon application of the following "evolutionary parsimony" principles:

1. If a feature is not required in order to explain the adaptive behavior of an organism, then one should not infer the existence of that feature; and

2. If a feature is not required for an organism's survival and reproduction, then it will not arise through evolution, or at least will not become established in that organism's evolutionary lineage.

Note that the second principle is not an epistemological parsimony claim; it is a claim about how evolution in fact works, and the first principle may be considered its epistemological derivative. This evolutionary parsimony represents an "adaptationist" approach to evolutionary theory, which has come under serious challenge in the past decade and a half. ${ }^{13}$ The specific type of adaptationism on which Harrison's position depends is, I believe, an excessively strong one-a claim that organisms in evolutionary lineages will eventually find the most effective ways to adapt themselves to particular circumstances, as if organisms were infinitely malleable adaptation machines. Before criticizing Harrison's position on this basis, I will point out two ways in which consideration of parsimony can support the claim that animals do feel pain.

A straightforward way in which parsimony can be invoked to support a case for animal pain is as follows: Since animals have the same structures that produce pain in humans, an account of animals in which they do not feel pain must invoke additional principles to account for this difference. It would be more parsimonious to use an account in which such extra principles are not required; namely, one in which similar causes produce similar effects and in which animals, like humans, feel pain. In this case the burden of proof would be on pain opponents to find relevant disanalogies between human and animal cases.

One can also use consideration of parsimony to support a case for conscious states in general, as Donald Griffin has attempted to do. He has argued, with limited success, that some patterns of behavior, and the intricacies of processing demanded by some behavioral tasks, are so complex that consciousness could actually be a more efficient mechanism for these than made-for-the-occasion neurological circuitry. According to Griffin:
It may be helpful, and even parsimonious, to assume some limited degree of conscious awareness in animals, rather than postulating cumbersome chains of interacting reflexes and internal states of motivation. ${ }^{14}$

Although the assumption that animals feel pain may not be strictly necessary to explain their behavior, it does not follow from this that pain could not be an evolutionary adaptation. The appropriate question in adaptive evolutionary terms is: Is pain the best available option, or was it the best available one during the period in which it arose? Is (or was) it, for example, more efficient in "neurological economy" to have a mechanism to create a feeling of pain, or instead to have a set of reflexes ready-made or developed for every occasion? It might have been (and might still be) advantageous for pain to be the cause of an action, not merely an extra, and therefore unnecessary, cause. If one grants the adaptive efficiency of consciousness as the arena for at least some animal decisions-whether the decisions are automatic or not-then pain can serve within this arena as the "voice of the body." Pain, in this account, would not require that animals make "free" choices. I say this in spite of the fact that one may challenge Harrison's assumption that animals do not choose freely, as well as his assumption that humans do choose freely.

Pain may not be the most efficient way to make an animal behave appropriately. However, evolution does not always produce the absolutely best or most efficient adaptation, but only the best or most efficient one given the material available (i.e. heritable physical features and genetic variance of such features). Evolution does not mold creatures freely, but instead operates within the limits of the genetic endowment and the constraints of developmental systems inherited from evolutionary forbears. For example, we breathe in and out, with an inefficient tidal respiration system that wastes most of the oxygen we take in and that voids carbon dioxide rather poorly. It is certainly less efficient than the "flowthrough" respiratory system of birds. However, we had to settle for what we received-and were stuck withfrom the therapsid reptile forbears. Birds, who have apparently descended from a different lineage - that of the dinosaurs-were not so constrained.

Similarly, pain might be "the best we higher animals could get." A reflex-generation system might be the most efficient mechanism of adaptation for a robot, 
which we can design from the start or by modifying another robot. It may not have been the most efficient way, however, for a lineage of our vertebrate ancestors that had inherited their neuroanatomy from primitive placoderm fish or lancelet-like chordate ancestors.

It may help at this point to distinguish two versions of the second evolutionary parsimony principle, based primarily on different substitutions for the expression, 'not required:' In one case, 'not required' is identified with 'useless'; in the other case, it is identified with 'not the best possible way' (in which case a feature is not required because a better alternative is available). This gives us the following:

2a) If a feature is useless for promoting an organism's survival and reproduction, then it will not become established in that organism's evolutionary lineage.

2b) If a feature is not the best possible way of promoting an organism's survival and reproduction, then it will either not become established in that organism's evolutionary lineage, or will be replaced by a better alternative.

Principle $2 b$ is the one that has been under attack here. However, principle $2 a$ is comparatively reasonable (in spite of the fact that it is not true without some qualification ${ }^{15}$ ), and when people assent to the second evolutionary parsimony principle as originally stated, they are likely to have something like $2 a$ in mind. Harrison would have a much stronger case if pain were actually useless as an adaptation, as it would be in plants, for example, since they cannot take action to remove themselves from the dangers that would be signaled by pain. Because pain would in fact have no benefit in such a case we would not expect it to be preserved in evolution. ${ }^{16} \mathrm{I}$ will note here that one of the reasons why Harrison can turn the tables on the adaptive-evolutionary argument for animal pain is that such an argument actually presents a much stronger negative case against pain in plants, and in sessile animals such as sponges, than it does a positive case for pain in animals.

Pain is certainly not useless for animals, and it is conceivable that it either is the best way to promote appropriate danger-avoidance behavior or was the best available such way during a crucial period in early vertebrate evolution. However, is it true that it either is or was the best available such option? We don't know. In order to know we need to know much more about the neurophysiology associated with conscious pain states, and perhaps that associated with states of consciousness in general. Until we do so, we cannot tell whether consciousness is more efficient than "hardwired" adaptations, because we do not yet now exactly what it is we are comparing. To evaluate the evolutionary claims we would need further information on the evolution of neural structure and its genetic basis. I am aware, of course, that I may be grossly understating the enormity and complexity of such tasks. Nevertheless, support for Harrison's position seems to require tackling them, since evolution works not on isolated mental states, but on the physical ones that produce or modify them, and only ones that are under genetic control.

Given our ignorance in such matters, and given the inability of a priori evolutionary theorizing and appeals to parsimony to settle the question of animal pain, the moral benefit of doubt in favor of animals should prevail. This does not mean that we must assume that animals such as flatworms, jellyfish and barnacles feel pain, or that they feel it as fully as we do. But it means that we must be willing to accept the uncertainty that is involved in dealing with a complex combination of neurophysiological, behavioral, and evolutionary evidence, and that we be willing to fall into occasional anthropomorphic error. And one may even change one's mind, as has Peter Singer, who once drew the line "somewhere between a shrimp and an oyster" but has since removed bivalve mollusks from his diet, although this is in part because "it is so easy to avoid eating them."17

It also means that those who wish to deny the existence or the magnitude of pain in animals, either specifically or in general, have the burden-as well as the opportunity - of identifying disanalogies between human states and animal states that would support such claims. It is quite possible that the conclusions of such studies will be highly unfriendly to those who wish to protect animals. However, such studies will have to be empirical - and often more messy and inconclusive than anyone would like-rather than a prioristic. We must look to the animals, not just to the theories of those such as Darwin and Lloyd Morgan.

\section{Notes}

1 Peter Harrison, "'Theodicy and Animal Pain," Philosophy 64:79-92(1989), p. 87; "Do Animals Feel Pain?," Philosophy 66:25-40 (1991), pp. 28-31. 
${ }^{2}$ Harrison, "Theodicy and Animal Pain," p. 85.

${ }^{3}$ Harrison, “Do Animals Feel Pain?," p. 29.

${ }^{4}$ Ibid.. P 30

${ }^{5}$ Marian Dawkins writes, for example: "To say that birds do not suffer because their brains are different from those of mammals is like stating that a jet airplane cannot fly because it has no propellers. Different anatomical structures can serve the same function..." (from "Author's Response," Brain and Behavioral Science 13:49-54, p. 50).

${ }^{6}$ Harrison, "Do Animals Feel Pain?," p. 35.

${ }^{7}$ Harrison, "Do Animals Feel Pain?," pp. 36, 38; "Theodicy and Animal Pain," p. 84.

${ }^{8}$ Harrison, "Do Animals Feel Pain?," p. 34.

${ }^{9}$ Harrison, "Theodicy and Animal Pain," p. 86.

${ }^{10}$ Harrison, "Do Animals Feel Pain?," p. 36

11 Donald Griffin's works, The Question of Animal Awareness (New York: Rockefeller Univ. Press, 1981) and Animal Thinking (Cambridge: Harvard Univ. Press, 1984), are directed largely to attacking the anti-mentalist bias that he saw among ethologists and psychologists.

${ }^{12}$ Harrison, "Theodicy and Animal Pain," pp. 88-91.

${ }^{13}$ See, for example, Stephen J. Gould and Richard C. Lewontin, "The Spandrels of San Marcos and the Panglossian Paradigm: A Critique of the Adaptationist Programme," Proceedings of the Royal Society of London B205:581-598, 1979.

${ }^{14}$ Griffin, The Question of Animal Awareness, p. 145. See also Animal Thinking, p. 40.

15 The principle is not true as stated because there are many features of organisms that have little or no apparent adaptive value. (I consider the issue of what proportion of features are nonadaptive to be an open one.) However, if a feature has a "cost" or disadvantage to it, or if it is likely to have had a fairly complex evolutionary development, it is reasonable to expect some adaptive function to be present to offset whatever disadvantages it may have now or may have had during its development. However, one could still be mistaken: In some cases, disadvantageous features may simply be genetically or developmentally linked to other features that are advantageous.

${ }^{16}$ See, for example, Marian Dawkins' argument in "Minding and Mattering," in Mindwaves, eds. C. Blakemore and S. Greenfield (Oxford: Blackwell, 1987), p. 159.

${ }^{17}$ Peter Singer, Animal Liberation (New York: Avon, 1990) p. 174.

\section{Response:}

Parsimony Made Simple: Rosenfeld on Harrison and Animal Pain

\section{David Boonin-Vail Georgetown University}

Peter Harrison stands accused of misusing the notion of parsimony. ${ }^{1} \mathrm{He}$ argues ${ }^{2}$ that we ought not to attribute pain states to animals on the grounds that doing so would be unparsimonious; the most efficient adaptive mechanisms possible for creatures lacking the ability to make free, reason-based choices ${ }^{3}$ would not require such states, and on "the simplest application of the theory of natural selection," ${ }^{4}$ we should not attribute to animals any features which are not required to explain their adaptive behavior. Rosenfeld objects that this conclusion implicitly presupposes the excessively strong claim that organisms always develop the most effective adaptive mechanisms possible, rather than the more realistic claim that they will tend to develop the most effective mechanisms available given the genetic material they have to work with. On this more reasonable standard, Rosenfeld argues, it remains an open possibility that the ability to feel pain (and, I would add, pleasure) was the best mechanism available at some important early stage in evolution, and that evolutionary theory might thus provide support for the attribution of pain to animals after all.

I want here to initiate the project of assessing the case for the prosecution by doing three things: first, I want to try to clarify the nature of the charge itself, by situating Rosenfeld's attack on Harrison's appeal to parsimony in this case within the context of a more fundamental attack on appeals to parsimony in general.

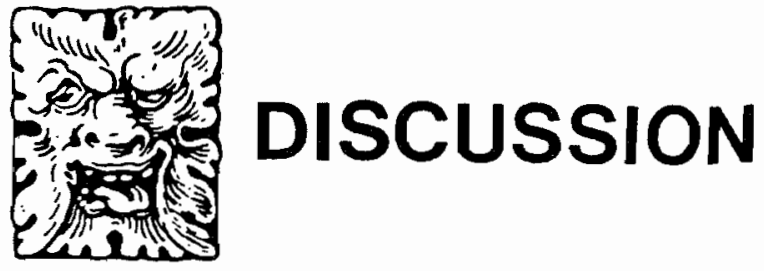

